MATEC Web of Conferences 38, 01010 (2016)

DOI: $10.1051 /$ matecconf/20163801010

(C) Owned by the authors, published by EDP Sciences, 2016

\title{
An Experimental Measurement on Laminar Burning Velocities and Markstein Length of Iso-Butane-Air Mixtures at Ambient Conditions
}

\author{
Alaeldeen Altag Yousif ${ }^{1, a}$, Shaharin A. Sulaiman ${ }^{1}$ and Mohammad Shakir Nasif ${ }^{1}$ \\ ${ }^{1}$ Department of Mechanical Engineering, Universiti Teknologi PETRONAS, 32610 Bandar Seri Iskandar, Perak, Malaysia
}

\begin{abstract}
In the present work, experimental investigation on laminar combustion of iso-butane-air mixtures was conducted in constant volume explosion vessel. The experiments were conducted at wide range of equivalence ratios ranging between $\Phi=0.6$ and 1.4 and atmospheric pressure of $0.1 \mathrm{MPa}$ and ambient temperature of $303 \mathrm{~K}$. Using spherically expanding flame method, flame parameters including stretched, unstretched flame propagation speeds, laminar burning velocities and Markstein length were calculated. For laminar burning velocities the method of error bars of $95 \%$ confidence level was applied. In addition, values of Markstein lengths were measured in wide range of equivalence ratios to study the influence of stretch rate on flame instability and burning velocity. It was found that the stretched flame speed and laminar burning velocities increased with equivalence ratios and the peak value was obtained at equivalence ratio of $\Phi=1.1$. The Markstein length decreased with the increases in equivalence ratios, which indicates that the diffusion thermal flame instability increased at high equivalence ratios in richer mixture side. However, the total deviations in the laminar burning velocities have discrepancies of $1.2-2.9 \%$ for all investigated mixtures.
\end{abstract}

\section{Introduction}

With the rapidly increasing depleting of energy resources and the strengthening of air and ground transportation pollutant legislations, the use of alternative fuels like liquefied petroleum gas (LPG) in engines has attracted more attention [1]. Liquefied petroleum gas (LPG) which considered as one of the main energy source in the commercial applications and domestic usages, containing different components of pure gases like propane, iso-butane or n-butane. The advantages of LPG such as clean fuel, has stable flame, no sulphur contents, high heating value and low ash [2]. In addition, due to the chemical complication of practical liquid fuels, such as gasoline, diesel and kerosene, contains hundreds of hydrocarbons and their combustion properties cannot be modelled and understood from first principle [3]. Iso-butane is selected as a surrogate hydrocarbon fuel for its significance to gasoline. Laminar burning velocity and Markstein length of hydrocarbon fuels are fundamental properties and plays an important role in understanding the behaviour of the flame instabilities and fuel burning rate in the internal combustion engines and different combustible systems [4].

Furthermore, regarding to the property of fuel-air mixtures, accurate determination of laminar burning velocity of heavy hydrocarbon fuels like iso-butane, is important for validation of the numerical models [5]. However, there are several studies in laminar burning velocities of different hydrocarbon fuels such as propane, n-butane and LPG. Iso-butane as a component of LPG,

\footnotetext{
${ }^{\mathrm{a}}$ Corresponding author: a.altagyousif@gmail.com
}

which is different from n-butane and LPG has a limited data on the laminar burning velocity and Markstein length.

In recent years different studies have been performed to study the laminar burning velocity and Markstein length of propane, LPG, n-butane and iso-butane-air mixtures. Abdulwahid et al. [6] investigated experimentally in burner plate, the laminar flame and thermal instabilities of $\mathrm{C}_{4} \mathrm{H}_{10^{-}}$ $\mathrm{C}_{3} \mathrm{H}_{8}$-air mixtures. The results show that at low equivalence ratios the flame is more willing to cellular instabilities. Using the expanding flame method, Liao et al. [1] explored the effect of preheat temperature and pressure in the laminar flame speed and Markstein length of LPG-air mixtures. The results show that the laminar burning velocities increased with increasing the pre-temperature of the mixtures and vice versa for initial pressure. In addition, $\mathrm{Vu}$ et al. [7] used same procedure studied the laminar burning velocities of LPG-air mixtures in different pre-heat temperature. Due to the increasing of preheat temperature an increasing in the laminar burning velocities were observed. Furthermore, Miao et al. [2] reported that the laminar burning velocity of LPG-air is increased significantly with hydrogen addition, while the flame thickness decreased with hydrogen addition. Kelley et al. [8] studied the nonlinear effects in the dynamic nature of laminar burning velocity of n-butane-air mixtures. They reported that the accuracy and feasibility of the extrapolation of n-butane enhanced by using smaller ignition energies and larger chambers. In addition, Bosschaart et al. [9] investigated the laminar burning velocity in mixtures of n-butane, iso-butane-air mixtures using heat flux burner. The deviations of this method are 
relatively large in the lean and rich flames. Furthermore, Davis et al. [10] investigated the laminar flame speeds of nbutane and iso-butane-air flame using counterflow method. N-butane-air flames showed higher laminar burning velocity than n-butane-air mixtures.

From the literature review, it is apparent that most of researchers work concentrated on studying the laminar burning velocities of LPG and n-butane rather than studying of iso-butane as pure fuel. A few reports have studied the convergence of laminar burning velocity data of iso-butane. Therefore, this fuel is not considered as important to determine its flame characteristics. Hence, the main objective of present study has intended to investigate experimentally the stretched flame propagation speeds, laminar burning velocities, Markstein length, of isobutane-air at constant volume explosion vessel. The measurements are made at ambient temperature of $303 \mathrm{~K}$, atmospheric pressure of $0.1 \mathrm{MPa}$ and equivalence ratios between 0.6 to 1.4 . The technique of flame analysis which is used in the present study is a different approach from the earlier ones. It involves renaming, thresholding and image boundary tracing as another image processing technique sequence coding. Furthermore, the results obtained from this study will be helpful in validation of chemical kinetic mechanisms and can be used as data base for understanding the behaviour of liquid fuel like gasoline.

\section{Experimental Technique}

In present work, the experiments of iso-butane-air mixtures were performed in a constant volume explosion vessel. The explosion vessel has an inside dimension of $360 \mathrm{~mm} \times 360$ $\mathrm{mm}$, as shown in Figure 1. Two windows quartz were located on the two sides of the vessel to make the inside observable to provide the optical access. The combustible mixture of iso-butane and air is prepared inside the vessel according to their partial pressures.

Two stainless steel electrodes were located at the centre of the vessel to ignite the combustible mixtures. To produce the spark, an automotive capacitive discharge ignition system was used. To visualize and record the flame development, a schlieren optical system with high speed digital camera phantom V9.2 with 1000 frame per second were used. To give the temperature information of the combustible mixture a K-Type thermocouple was installed inside the vessel. Since the pre-conditions of the mixtures are $303 \mathrm{~K}$ and $0.1 \mathrm{MPa}$, a digital pressure gauge was used to measure the mixture pressure. The explosion vessel was evacuated and flushed with purified air before each test to ensure no combustion products remained and reduce the temperature of the vessel. However, to ensure the accuracy of the data obtained and repeatability for each experiment condition, three times repeated tests were done.

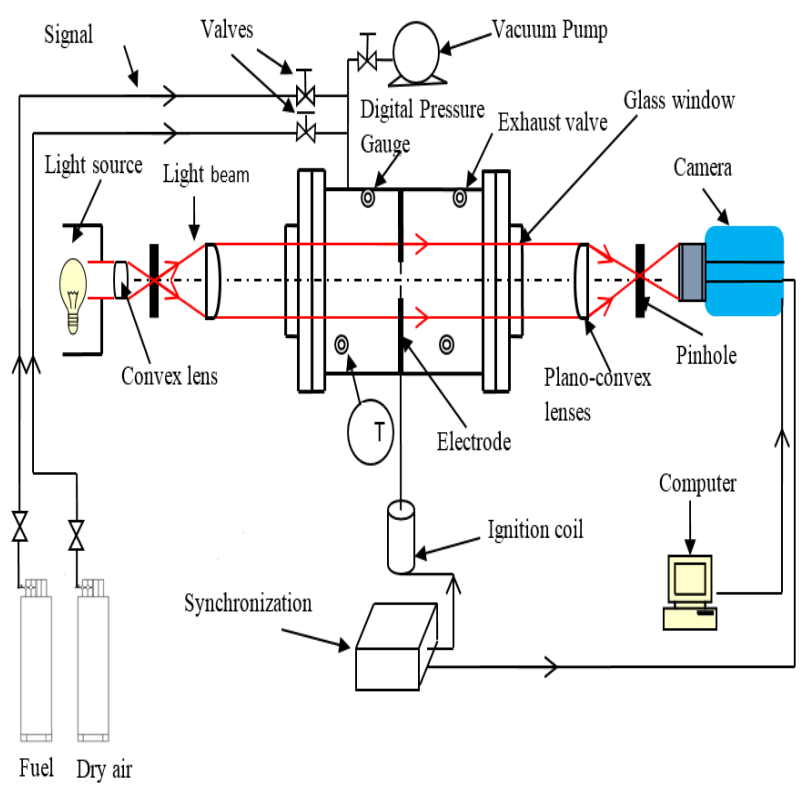

Figure 1. Schematic of the experimental system.

The mixture of iso-butane-air was injected inside the explosion vessel using the partial pressure method, as well as, the equivalence ratio $(\Phi)$ was determined. To ensure the homogeneity and complete diffusivity, the combustible mixtures of iso-butane-air were remained for ten minutes inside the explosion vessel before ignition take place. The deviation of mixture temperature is about $\pm 1 \mathrm{~K}$ for all experimental test. In addition, to reduce the uncertainties, at least three runs have been made for each mixture and the average was taken. However, the deviation in three runs of each experimental test was found be less than $5 \%$.

\section{Results and Discussion}

\subsection{Stretched Flame Propagation Speeds and Laminar Burning Velocity}

The stretched and unstretched laminar burning velocities measurements of iso-butane-air flames are obtained for different equivalence ratios at atmospheric pressure of 0.1 $\mathrm{MPa}$ and ambient temperature of $303 \mathrm{~K}$. A 35 frames for each test are taken, covering the period of free flame propagation, from ignition time to wall effects. Linear extrapolation is applied to find out the unstretched laminar flame speed.

When the combustible mixture of iso-butane-air flame is ignited in the center of the combustion chamber, an outwardly spherical propagation flame develops. However, the stretched flame front propagation is likely influenced by the electrodes cooling effects, and the flame may lose the flame front wrinkles and its stability causing non-sphere flame, so the radii of flames in vertical direction are used. In present experimental investigation, most of the flames have smooth front surface. Therefore, the cellular structure of the flame which accelerates the flame is not considered.

In the present experimental configuration, the stretched flame propagation speed of iso-butane-air mixtures at wide range of equivalence ratio was measured and plotted. The 
spherical expanding flames of schlieren photographs as shown in Figure 2 were obtained to measure the flame radii at different times. The minimum radius of flame propagation starting from $3.9 \mathrm{~mm}$ and the maximum measured possible radius is $54 \mathrm{~mm}$ for iso-butane-air flames at $0.1 \mathrm{MPa}$ and $303 \mathrm{~K}$. After the radius of $52 \mathrm{~mm}$, it can be seen clearly that the flame speed starts to decrease. This decrease of flame speed is due to the effect of stretch, small diffusivity of iso-butane as heavy fuel and the light increase in the combustible mixtures pressure.

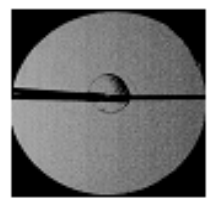

$\mathrm{t}=8 \mathrm{~ms}[\mathrm{r}=9 \mathrm{~mm})$

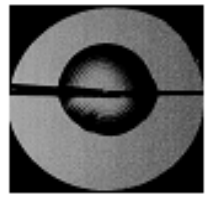

$\mathrm{t}=16 \mathrm{me}$ Ir $=24 \mathrm{mml}$
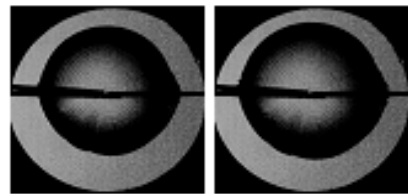

$t=24 \mathrm{~ms}(r=40 \mathrm{~mm}) \quad \mathrm{t}=26 \mathrm{~ms}(\mathrm{r}=44 \mathrm{~mm})$

$\mathrm{t}=28 \mathrm{~ms}[\mathrm{r}=50 \mathrm{~mm})$

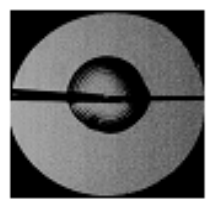

$\mathrm{t}=14 \mathrm{~ms}[\mathrm{r}=18 \mathrm{~mm})$

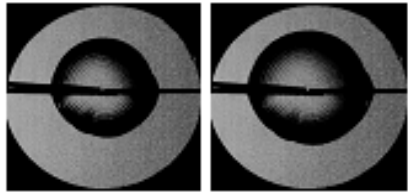

$\mathrm{t}=20 \mathrm{~ms}$ Ir $=32 \mathrm{mml}$
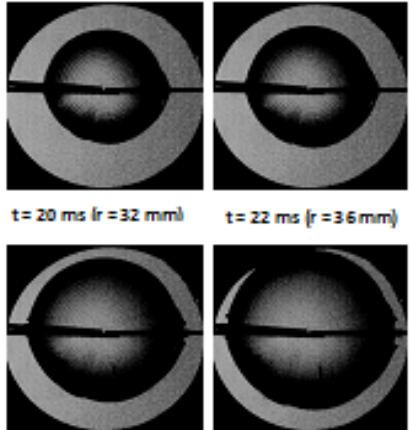

$\mathrm{t}=22 \mathrm{~ms}(\mathrm{r}=36 \mathrm{~mm})$

Figure 2. Flame images for iso-butane-air mixtures at $\Phi=1.0$.

Figure 3 shows the variations of flame radius development inside the combustion chamber versus the time of iso-butane-air mixtures at stoichiometric equivalence ratios of $\Phi=0.6$ to 1.4. As shown in the figure, the stretched flame expands spherically when the ignition takes place from the schlieren photographs and the flame radius increased rapidly in the following process.

A Linear correlation exists between flame radius and elapsing time for all iso-butane cases. As shown in Figure 3 , the fastest rate of flame propagation is occurred in stoichiometric mixture at $\Phi=1.1$, where the flame radius increased rapidly after ignition took place. While the slope decreases is observed moving away towards the rich and the lean mixtures. However, the lowest radii occurred for the leanest mixture $(\Phi=0.6)$. According to the Markstein view, the slope of the radius-time plot reflects the influence of stretch rate on flame [11].

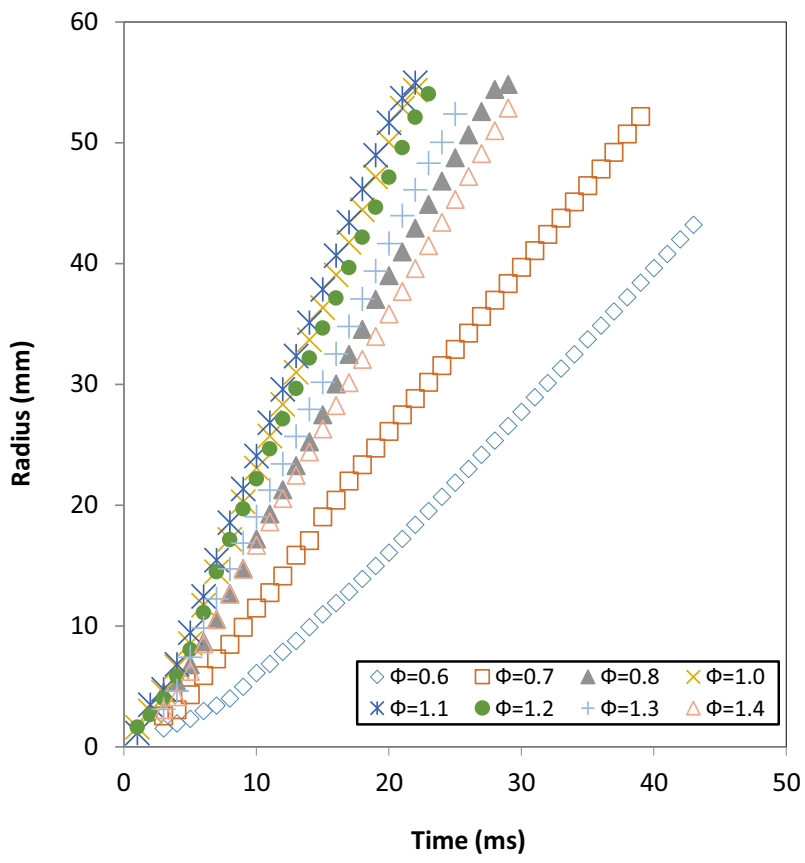

Figure 3. Flame radius versus elapsing time of ignition for isobutane-air mixtures at $\mathrm{P}=0.1 \mathrm{MPa}$ and $\mathrm{T}=303 \mathrm{~K}$.

For stable flame, the slope of the radius-time plot increased with the flame expansion, while for unstable flame front, the gradient of the radius-time plot decreased with the flame expansion. Thus, in present investigations, stable flames are presented for iso-butane-air mixture for most tested mixtures.

Figure 4 shows the stretched flame propagation speed against flame radius at wide range of equivalence ratios and ambient conditions for iso-butane-air flames. The stretched flame propagation speed, $S_{b}$ was obtained using the following equation [12]:

$$
S_{b}=\frac{d r}{d t}
$$

where $r$ is the flame radius in $\mathrm{mm}$ and $t$ is the elapsing time from spark ignition starting in ms.

As shown in the Figure 4, the stretched flame propagation speed is increased linearly with flame radius for all investigated mixtures when the flame radius is greater than $5 \mathrm{~mm}$. In the meantime, the stretched flame propagation speed is increased as equivalence ratio increased. It is evident that the stretched flame propagation speed is highest for stoichiometric mixture of $\Phi=1.1$ for any flame size, while the lowest value of stretched flame propagation obtained in leanest mixture of $\Phi=0.6$. 


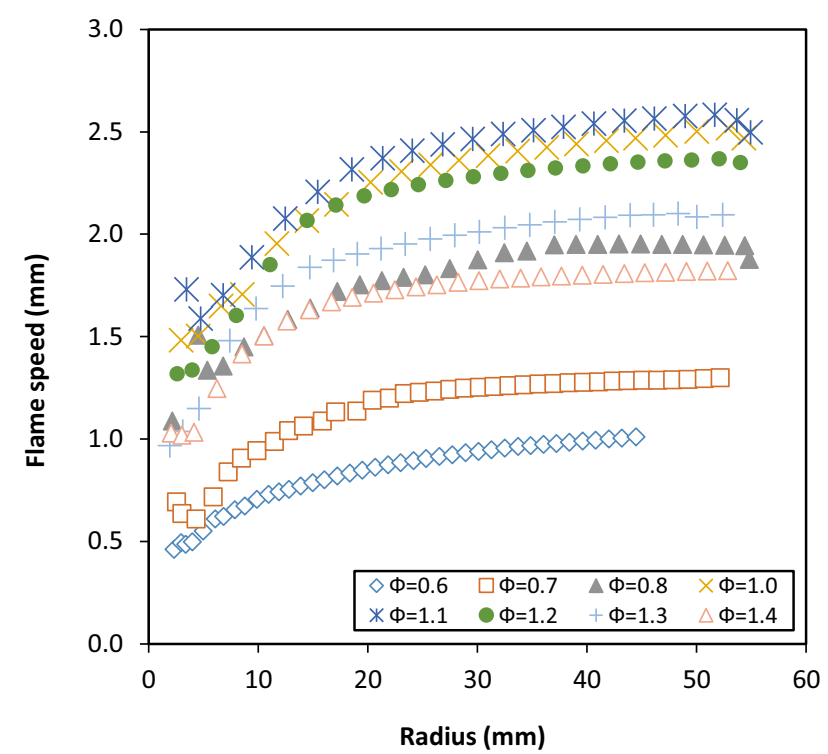

Figure 4. Stretched flame speed versus flame radius for different iso-butane mixtures at $\mathrm{P}=0.1 \mathrm{MPa}$ and $\mathrm{T}=303 \mathrm{~K}$.

The flame growth rate for leanest $(\Phi=0.6)$ or richer mixtures $(\Phi=1.4)$ becomes smaller and it takes longer time to burn compared to the stoichiometric of $\Phi=1.1$. This indicates that the stoichiometric mixture reaches the corresponding unstretched flame speed faster because the stretch sensitivity is very weak around the stoichiometric mixture.

As mentioned previously, the stretched flame speed is obtained by the derivative of flame radius with elapsing of the ignition. In addition, the stretched flame speed represents the flame moving speeds relative to the combustion wall. Figure 4.32 shows the stretched flame front propagation speed for lean, stoichiometric and rich mixtures of iso-butane-air flames versus stretch rate under initial conditions of $0.1 \mathrm{MPa}$ and $303 \mathrm{~K}$. Also the Figure shows clearly the effect of stretch rate on flame propagation speed. The total stretch rate of the flames $\alpha$ is defined as [13]:

$$
\alpha=\frac{1}{A} \frac{d A}{d t}=\frac{2}{r} S_{b}
$$

As shown in Figure 5 Linear relationship between stretched flame propagation speed and stretch rate was observed. For this reason, the linear extrapolation method is applied to iso-butane-air flames at all equivalence ratios. The variations of stretched flame speeds as function of flame stretch rate are demonstrated. At the initial stage of flame growth when the stretch is predominant, a significant variation on flame speed of reactant mixtures is observed. For all investigated mixtures, the acceleration of stretched flame propagation caused by the decreasing of stretched rate (increase of flame radius) which indicates the Markstein length has appositive value. In addition, the equivalence ratio has the same effect in the slope of stretched flame speed and stretch rate. The stretched flame propagation speed increased as equivalence ratio increased. Furthermore, the largest decreasing rate in stretched flame propagation speed is observed in the leanest mixture ( $\Phi=$ 0.6 ). The plot of stretched flame speed versus stretch rate is used to obtain the values of unstretched flame propagation speed. Unstretched laminar flame speed is then obtained directly by extrapolated the data of stretched flame speed to zero stretch rate.

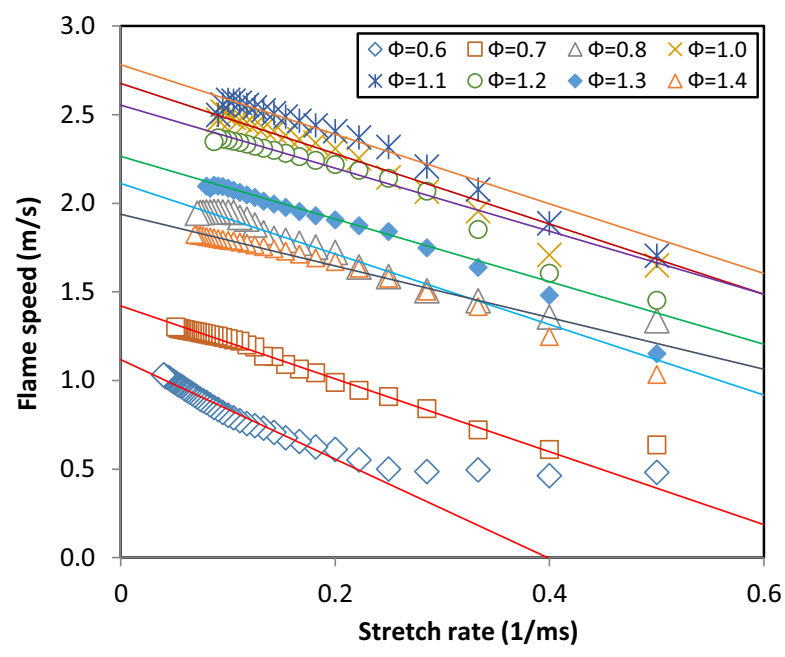

Figure 5. Stretched flame speed versus stretch rate for isobutane-air mixtures at $\mathrm{P}=0.1 \mathrm{MPa}$ and $\mathrm{T}=303 \mathrm{~K}$.

In Figure 6, the unstretched flame speed is plotted as function of equivalence ratio of iso-butane-air flames at $\mathrm{P}=0.1 \mathrm{MPa}$ and $\mathrm{T}=303 \mathrm{~K}$. The unstretched flame propagation speed, $S_{u}$ and values of Markstein length, $L_{b}$ were measured using the following equation [14]:

$$
L_{b}=\frac{S_{u}-S_{b}}{\alpha}
$$

The unstretched flame propagation speed increased with equivalence ratio. The peak value of unstretched flame propagation speed obtained at equivalence ratio of $\Phi=1.1$. However, the increasing unstretched laminar flame propagation of each mixture occurred due to the decrease of stretch effect when the flame grew. Moreover, as observed in the figure, from stoichiometric mixture, the flame front sensitivity to the stretch rate is increased towards the lean and rich side mixtures. This flame behaviour should be considered as an important aspect for practical cases.

As discussed earlier in the literature review, very few experimental and simulation data are available for laminar burning velocity and Markstein length of iso-butane-air mixtures. Thus, the measured laminar burning velocities of iso-butane-air flames of present work were compared with data of iso-butane and n-butane-air mixtures from previous literature to validate the present data. In order to measure the values of the laminar burning velocities from the obtained unstretched flame propagation speed, the following equation was used [8]:

$$
S_{i}=S_{u}\left(\frac{\rho_{b}}{\rho_{u}}\right)
$$




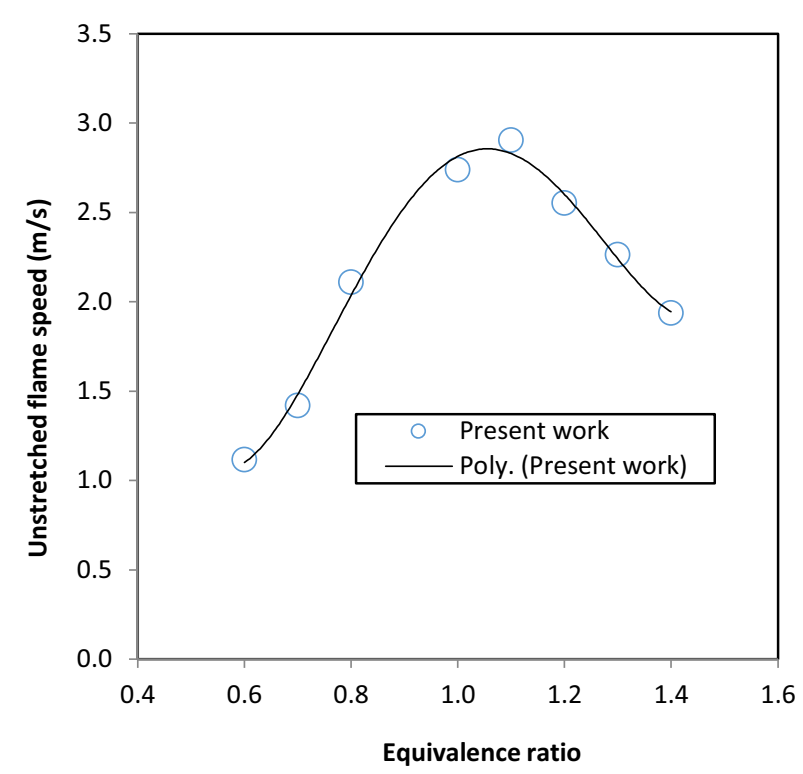

Figure 6. Unstretched flame speed versus equivalence ratio for iso-butane-air mixtures at $\mathrm{P}=0.1 \mathrm{MPa}$ and $\mathrm{T}=303 \mathrm{~K}$.

The values of the laminar burning velocity $S_{i}$ of isobutane-air mixtures which have been extracted using the Eq. 2.4 are plotted in Figure 7 against the equivalence ratio. The iso-butane unstretched laminar burning velocity shows slight shift towards the fuel-rich region like the behavior of ethane-air flames, where the peak burning velocity obtained at $\Phi=1.1$. This trend is similar to those observed in previous studies $[9,10]$, whose values of unstretched laminar burning velocity were also extracted linearly. In addition, both the systematic $\left(\mathrm{P}_{\mathrm{SL}}\right)$ and random $\left(B_{S L}\right)$ uncertainties of laminar burning velocities in present work were performed as shown in Figure 7. However, the maximum percentage of uncertainty was found to be near $3 \%$ and it is within the acceptable range of uncertainties measurements.

A comparison of laminar burning velocity between present work and different techniques of heat flux method of Bosschaart et al. [4] and Davis et al. [10] are also presented in 7. It can be seen that the present data shows good agreement with the results from $[9,10]$.

The influence of equivalence ratio on the unstretched laminar burning velocity is the same for present work and the other methods like heat flux method, but the value of laminar burning velocity of present work is higher than those obtained by heat flux method of 3-5\% and lower of $6 \%$ than that obtained by Sung et al. [15] which is calculated by using computational study. Furthermore, the present results are slightly lower than the data of n-butaneair mixtures obtained by Davis et al. [10] and in good agreement with n-butane data of Kelley et al. [8]. As shown in Figure 7, the n-butane-air mixtures shows higher laminar burning velocity compaired to iso-butane-air mixtures and this difference is due to the higher heat of combustion for n-butane than iso-butane.

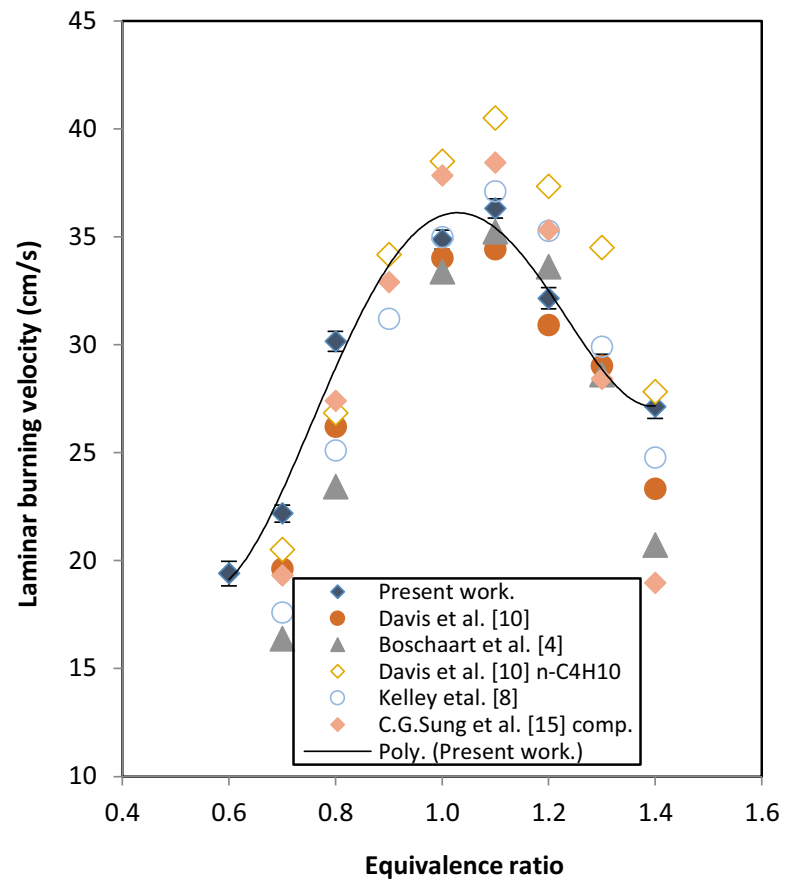

Figure 7. Laminar burning velocity versus equivalence ratio for iso-butane-air mixtures at $\mathrm{P}=0.1 \mathrm{MPa}$ and $\mathrm{T}=303 \mathrm{~K}$.

\subsection{Markstein Length measurements}

The Markstein length is characterizes the responses of flame to stretch. For heavy hydrocarbon fuel-air mixtures, Markstein length increases with the decrease of equivalence ratio [17]. Since iso-butane is a heavy hydrocarbon fuel, hence Markstein lengths under all conditions decreased with increase of equivalence ratios as shown in Figure 8 which means the sensitivity of stretch increases at high equivalence ratio. This showed that the lean fuel-air mixtures have higher stability compared to the rich fuel-air mixtures. This trend is similar to that of LPGair mixtures as reported in [1]. This indicates that in ambient conditions, the flame front propagation is less affected by the stretch rate and the flames of iso-butane-air mixtures are stable, especially for rich mixtures. As mentioned above in this section, no data available on Markstein lengths of iso-butane-air mixture. Therefore, Markstein lengths of LPG-air mixtures from previous study of Liao et al. [1] were compared with present data as shown in Figure 8. Values of Markstein length in lean mixtures is lower than the values of Markstein length of LPG-air mixtures obtained by [1]. This difference may be due to the extrapolation method used for LPG-air mixtures. 


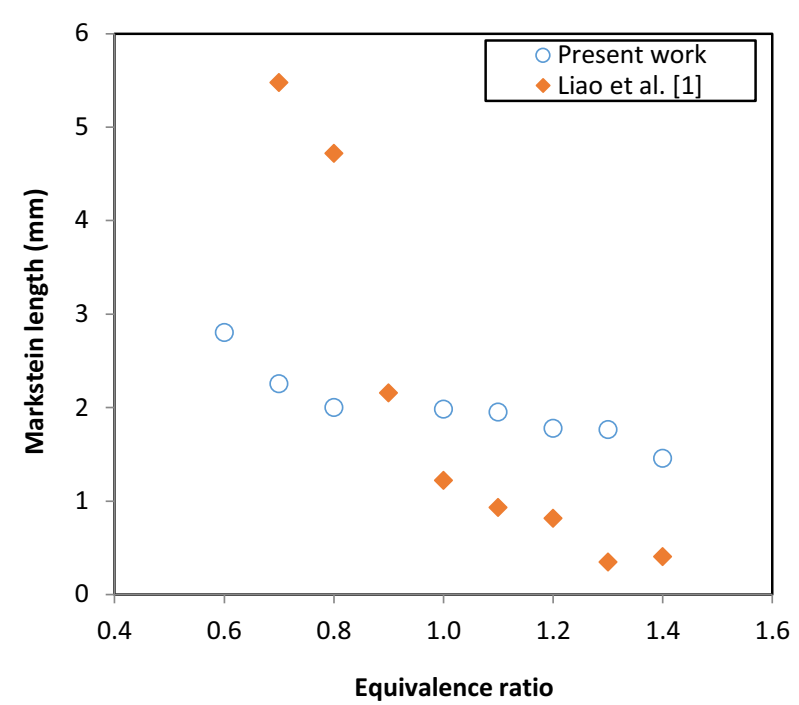

Figure 8. Markstein length versus equivalence ratio for isobutane-air mixtures at $\mathrm{P}=0.1 \mathrm{MPa}$ and $\mathrm{T}=303 \mathrm{~K}$.

\section{Conclusions}

An experimental investigation on laminar burning velocities and flame instabilities of Iso-butane-air mixtures at ambient conditions were performed using constant volume explosion vessel. In addition, the effect of Markstein length, on flame instability was experimentally investigated in wide ranges of equivalence ratios. Based on the obtained results, the findings conclusions are made:

1. The Markstein length for iso-butane as heavy fuel, decreased as equivalence ratio increased. This indicates that the flame instabilities for the heavy fuels is increased in richer mixture side.

2. Iso-butane flames showed lower burning rate than $n-$ butane, which indicates that the linear component of alkanes have higher burning rate compared to the corresponding branched alkane component. However, the values of laminar burning velocities of present work is higher than those obtained by heat flux method of 3$5 \%$.

\section{References}

1. S. Liao, D. Jiang, J. Gao, Z. Huang, and Q. Cheng, "Measurements of Markstein numbers and laminar burning velocities for liquefied petroleum gas-air mixtures," Fuel, vol. 83, pp. 1281-1288, (2004).

2. J. Miao, C. Leung, Z. Huang, C. Cheung, H. Yu, and Y. Xie, "Laminar burning velocities, Markstein lengths, and flame thickness of liquefied petroleum gas with hydrogen enrichment," international journal of hydrogen energy, vol. 39, pp. 13020-13030, (2014).

3. C. J. Ning Liu, Fokion N. Egolfopoulos, "Ignition of non-premixed $\mathrm{C}_{3}-\mathrm{C}_{12}$ n-alkane flames," Combustion and Flame, vol. 159, pp. 465-475, (2012).

4. E. M. Varea, Vincent Vandel, Alexis Renou, Bruno, "Measurement of laminar burning velocity and Markstein length relative to fresh gases using a new postprocessing procedure: Application to laminar spherical flames for methane, ethanol and isooctane/air mixtures," Combustion and Flame, vol. 159, pp. 577 590, (2012).

5. S. J. Liao, DM Huang, ZH Shen, WD Yuan, C Cheng, Q, "Laminar burning velocities for mixtures of methanol and air at elevated temperatures," Energy Conversion and Management, vol. 48, pp. 857-863, (2007).

6. M. Abdulwahid, K. M Saqr, M. Sies, and H. Ujir, "Diffusive thermal instabilities of $\mathrm{C}_{4} \mathrm{H}_{10}-\mathrm{C}_{3} \mathrm{H}_{8} /$ air laminar premixed flames," The Open-Access Journal for the Basic Principles of Diffusion Theory, Experiment and Application, vol. 9, pp. 1-8, (2009).

7. T. M. Vu, "Using Expanding Spherical Flames Method To Measure The Unstretched Laminar Burning Velocities Of LPG-Air Mixtures," Science and Technology Development, vol. 12, (2009).

8. A. Kelley and C. K. Law, "Nonlinear effects in the extraction of laminar flame speeds from expanding spherical flames," Combustion and Flame, vol. 156, pp. 1844-1851, (2009).

9. K. J. Bosschaart and L. De Goey, "The laminar burning velocity of flames propagating in mixtures of hydrocarbons and air measured with the heat flux method," Combustion and Flame, vol. 136, pp. 261269, (2004).

10. S. Davis and C. Law, "Determination of and fuel structure effects on laminar flame speeds of $C_{1}$ to $C_{8}$ hydrocarbons," Combustion Science and Technology, vol. 140, pp. 427-449, (1998).

11. E. B. Monteiro, Marc Sotton, Julien Moreira, Nuno Afonso Malheiro, Salvador, "Laminar burning velocities of typical syngas compositions, "in Proceedings of the European Combustion Meeting, pp. 14-17, (2009).

12. M. Baloo, B. M. Dariani, M. Akhlaghi, and I. Chitsaz, "Effect of iso-octane/methane blend on laminar burning velocity and flame instability," Fuel, vol. 144, pp. 264-273, (2015).

13. J.W. Chen, C.P. Chiu, S.H. Mo, and J.T. Yang, "Combustion characteristics of premixed propane flame with added $\mathrm{H}_{2}$ and $\mathrm{CO}$ on a $\mathrm{V}$-shaped impinging burner," international journal of hydrogen energy, vol. 40, pp. 1244-1255, (2015).

14. G. Jomaas, C. Law, and J. Bechtold, "On transition to cellularity in expanding spherical flames," Journal of Fluid Mechanics, vol. 583, pp. 1-26, (2007).

15. C. J. Sung, Y. Huang, and J. A. Eng, "Effects of reformer gas addition on the laminar flame speeds and flammability limits of n-butane and iso-butane flames," Combustion and Flame, vol. 126, pp. 16991713, (2001).

16. M. B. Matalon M, "Flames as gas dynamic discontinuities," Fluid Mechanic, vol. 124, pp. 239259, (1982).

17. J. Bechtold and M. Matalon, "The dependence of the Markstein length on stoichiometry," Combustion and Flame, vol. 127, pp. 1906-1913, (2001). 